\title{
Guideline for obtaining valid consent for gastrointestinal endoscopy procedures
}

\author{
Simon M Everett, ${ }_{1}^{1}$ Helen Griffiths, ${ }^{2}$ U Nandasoma, ${ }^{3}$ Katie Ayres, ${ }_{1}^{4}$ Graham Bell, ${ }^{5}$ \\ Mike Cohen, ${ }^{6}$ Siwan Thomas-Gibson, ${ }^{7}$ Mike Thomson, ${ }^{8}$ Kevin M T Naylor ${ }^{9}$
}

For numbered affiliations see end of article.

\section{Correspondence to} Dr Simon M Everett, Department of

Gastroenterology, Leeds Teaching Hospitals NHS Trust, Leeds Teaching Hospitals, Level 4, Bexley Wing, Leeds LS9 7TF, UK; Simon.everett@nhs.net

Received 22 March 2016 Revised 19 May 2016 Accepted 22 May 2016 Published Online First 20 June 2016
CrossMark

$$
\begin{aligned}
& \text { To cite: Everett SM, } \\
& \text { Griffiths H, Nandasoma U, } \\
& \text { et al. Gut 2016;65:1585- }
\end{aligned}
$$$$
1601 .
$$

\section{ABSTRACT}

Much has changed since the last guideline of 2008, both in endoscopy and in the practice of obtaining informed consent, and it is vital that all endoscopists who are responsible for performing invasive and increasingly risky procedures are aware of the requirements for obtaining valid consent. This guideline is restricted to $\mathrm{Gl}$ endoscopy but we cover elective and acute or emergency procedures. Few clinical trials have been carried out in relation to informed consent but most areas are informed by guidance from the General Medical Counsel (GMC) and/or are enshrined in legislation. Following an iterative voting process a series of recommendations have been drawn up that cover the majority of situations that will be encountered by endoscopists. This is not exhaustive and where doubt exists we have described where legal advice is likely to be required. This document relates to the law and endoscopy practice in the UK-where there is variation between the four devolved countries this is pointed out and endoscopists must be aware of the law where they practice. The recommendations are divided into consent for patients with and without capacity and we provide sections on provision of information and the consent process for patients in a variety of situations. This guideline is intended for use by all practitioners who request or perform GI endoscopy, or are involved in the pathway of such patients. If followed, we hope this document will enhance the experience of patients attending for endoscopy in UK units.

\section{SUMMARY OF RECOMMENDATIONS}

\subsection{General principles}

- Owing to the invasive nature and potential risks, we recommend that all endoscopic procedures of the GI tract require written consent, except in an emergency. Strong recommendation, moderate quality evidence.

- Although the process of consent can be delegated, we recommend that the endoscopist performing the procedure is ultimately responsible for ensuring that the consent process is appropriate for the procedure being undertaken. Strong recommendation, moderate quality evidence.

\subsection{Assessment of capacity}

- We recommend that the endoscopist performing the procedure ensures that the patient has capacity to consent to the procedure. If capacity appears to have changed since consent was first obtained then reassessment is required. Delaying the procedure to allow further adjustments or the opportunity to regain capacity may be appropriate, but a decision to proceed based on 'best interests' (see section 7, 'Patients considered not to have capacity') can also be considered if it is likely that capacity will not be recovered. Strong recommendation, moderate quality evidence.

\subsection{Provision of information}

- For all patients, we recommend that information should be provided in a format that they can understand about the expected benefits as well as the potential burdens and risks and alternatives of any proposed endoscopic procedure. Strong recommendation, moderate quality evidence.

- For outpatient elective procedures, we suggest that verbal and/or written information should be provided by the clinician recommending the endoscopy at the time of the consultation and this should be documented in the clinical notes. Weak recommendation, moderate quality evidence.

- For outpatient procedures, we recommend that written information should be provided in advance of the procedure with sufficient time for the patient to read, evaluate and seek further information if required. Strong recommendation, low quality evidence.

- We recommend that endoscopy units retain information leaflets that pertain to all standard endoscopic procedures performed regularly within that unit. They must retain a log of these information leaflets, when last updated and by whom, and each leaflet must be reviewed annually by endoscopy staff and incorporate questions frequently asked by patients. Strong recommendation, low quality evidence.

- We suggest that information leaflets should be available in languages common to the local population and should be reviewed by lay people. Weak recommendation, low quality evidence.

- Where procedure-specific information leaflets are not available (eg, for infrequent or specialist procedures) we recommend that the patient has the opportunity to discuss that procedure before the appointment with the endoscopist (or a delegated person), either face to face or by telephone, with the discussion clearly documented in the medical records. Strong recommendation, low quality evidence.

- Written information provides a minimum dataset but if an individual's risk is higher owing to frailty or comorbidity, we recommend that this be discussed and/or additional written information provided to reflect this risk and that 
information documented in the case notes. Strong recommendation, moderate quality evidence.

- We recommend that all patients be given the opportunity to express their individual concerns, and consent should reflect that discussion. Strong recommendation, moderate quality evidence.

- For inpatients, we recommend that, where available, written information is provided in an appropriate format to the patient before they leave the ward for the procedure, allowing sufficient time for the information to be read and questions to be asked. Where ward staff cannot answer the questions they must ensure that the patient is given access to someone who can. Strong recommendation, moderate quality evidence.

- For patients who decline information, we recommend that the minimum information should include the aims of the proposed investigation or treatment, the expected level of pain or discomfort and steps taken to minimise it. In addition, the level of risk related to the procedure that the patient wishes to know (or not) should be ascertained and recorded. Strong recommendation, moderate quality evidence.

- We recommend that it is ensured that the written information has been understood with particular reference to any material risks and that the patient is given the opportunity to ask questions or raise concerns and have these answered in a full, open and honest manner. Any concerns expressed by the patient, even if not in the form of questions, should also be dealt with in the same way. Strong recommendation, moderate quality evidence.

- For direct to test procedures, we recommend that the organisation receiving the referral puts in place pathways to ensure that the referral is appropriate and the patient adequately informed. Strong recommendation, low quality evidence.

\subsection{The consent process}

- Consent should be obtained by the endoscopist or delegated to a suitably trained individual. Strong recommendation, moderate quality evidence.

- The formal consent process should be completed before entry into the procedure room. Final validation of that process should occur before the procedure starts. Strong recommendation, low quality evidence.

\subsection{Consent as integral part of care pathway in endoscopy}

- Endoscopy units should incorporate a check within their patient pathway booklet or an adapted WHO safer surgery checklist that adequate and valid consent has been obtained before starting the procedure. Strong recommendation, moderate quality evidence.

\subsection{Consent for surveillance procedures}

- We recommend that consent should be sought in advance of all surveillance endoscopic procedures in the standard way. Strong recommendation, low quality evidence.

- If new information becomes available in relation to surveillance intervals or risk of disease, or if the patient's condition has changed, we recommend that the patient's agreement to remain in a surveillance programme should be reconfirmed. Strong recommendation, moderate quality evidence.

\subsection{Children}

- Young people aged 16-18 years are presumed to have the capacity to consent to endoscopy and related procedures. We recommend that endoscopists competent to perform the procedure in adults should apply similar principles in young people over 16. Strong recommendation, moderate quality evidence.

- Competent children aged < 16 years can consent to endoscopy but we recommend that competence should be confirmed by practitioners trained and experienced in doing so. Strong recommendation, low quality evidence.

- Where any doubt or conflict exists about consenting to endoscopy in a young person ( $<18$ years) or if the young patient refuses treatment we recommend that expert legal advice is sought. Strong recommendation, moderate quality evidence.

\subsection{Emergency endoscopy}

- In an emergency, full compliance with written consent may not be possible and in these circumstances we recommend that verbal consent is used but must be fully documented in the medical notes. Strong recommendation, moderate quality evidence.

- Where written or verbal consent cannot be obtained in an emergency we recommend that the action taken must be the least restrictive of the patient's future options. Strong recommendation, moderate quality evidence.

\subsection{Unexpected findings at endoscopy}

- Endoscopists should be careful to define the extent of consent before the procedure and consent should be taken for treatments that can reasonably be expected to occur during the procedure. The scope of that consent should not be exceeded unless failure to intervene would cause immediate harm. Strong recommendation, low quality evidence.

\subsection{Patients without capacity}

- We recommend that all endoscopists have sufficient understanding of the law on capacity and in relation to lasting powers of attorney (LPA), independent mental capacity advocates (IMCAs) and advance decisions to refuse treatment, as outlined in this document, to be confident that they can comply with its requirements when assessing capacity and taking consent. Strong recommendation, moderate quality evidence.

- We recommend that where a patient lacks capacity and there is a proxy decision-maker then the decision taken for endoscopy must be taken in the patient's best interests. When assessing a person's best interests the endoscopist must take into consideration the prior wishes of the patient and the views of those caring for the patient or with an interest in his welfare, such as family members. Any intervention must be the least restrictive of the person's future options and freedom. Strong recommendation, moderate quality evidence.

- For patients lacking capacity, we suggest that there is a multidisciplinary discussion and joint decision between the attending clinician and endoscopist about the best interests of the patient. The endoscopist should confirm that the procedure is in the best interests of the patient and sign consent form 4. Where local policies permit, both attending team and endoscopist should record their views on the consent form. Weak recommendation, low quality evidence.

\subsection{Withdrawal of consent}

- We recommend that where a person objects during an endoscopic procedure, the procedure should be stopped, and the person's concerns and capacity to withdraw consent 
established. It may be possible to restart after a suitable pause and reassurance. Strong recommendation, low quality evidence.

- If the patient appears to have capacity (whether sedated or not) and clearly indicates that he/she wishes the procedure to be discontinued then we recommend that this must occur immediately unless doing so would expose the patient to risk of serious harm. Strong recommendation, low quality evidence.

- We recommend that if, in the endoscopist's opinion, capacity is lacking, it may be justified to continue in the person's best interests. If stopping the procedure would put the person at risk of harm the practitioner may continue until that risk no longer applies. Strong recommendation, moderate quality evidence.

- We recommend that any circumstances in which consent is withdrawn should be noted on the endoscopy report and/or medical case notes. Strong recommendation, low quality evidence.

- We suggest that all endoscopy units should have a policy relating to withdrawal of consent. Weak recommendation, low quality evidence.

\subsection{Photography, video and live endoscopy events}

- We recommend that taking photos or videos during normal patient care in endoscopy does not require additional consent, but should be noted in the patient information leaflet. Strong recommendation, moderate quality evidence.

- We recommend that recordings taken at such times may be used for secondary purposes, such as teaching or assessment, without seeking additional consent, so long as the images are anonymised. Strong recommendation, moderate quality evidence.

- We recommend that patient-identifiable images or data should not be stored on personal mobile devices. Local employers' policies on data capture and retention must be followed. Strong recommendation, low quality evidence.

- We recommend that video transmission, as in live endoscopy events (LEEs) or for presentation that does not form part of standard patient care, requires additional written consent from the patient. Strong recommendation, moderate quality evidence.

\subsection{Nurse-led consent}

- We recommend that consent can be delegated to endoscopy nurses who have successfully completed competency training including direct observational practice evaluation. Strong recommendation, low quality evidence.

- We recommend annual evaluation of patient experience of the consent process and revalidation of knowledge and skills of individuals. Strong recommendation, low quality evidence.

\section{INTRODUCTION}

Since the publication of "Guidance for Obtaining a Valid Consent for Elective Endoscopic Procedures"-a report of the working party of the British Society of Gastroenterology early in 2008-General Medical Council (GMC) principles on obtaining consent were published later in 2008, the Department of Health (DoH) reference guide to consent was updated in 2009 and a number of other reference documents have been published.

Many aspects of GI endoscopy have changed since 2008. Far more endoscopies are now performed by a wider variety of practitioners. Therapeutic endoscopy is more commonplace and the risks of some procedures are higher, with a wider range of alternatives. Large numbers of patients are referred 'straight to test' by practitioners who do not necessarily have sufficient knowledge of the procedure and the risks, benefits and alternatives to the proposed investigations. Some patients are being managed outside the traditional outpatient setting through screening and surveillance pathways. It is now recognised that the patient pathway through the unit should incorporate endoscopy-specific safety checks while the workload of acute and inpatient endoscopy is increasing and requires specific guidance.

What has not changed since 2008 is that endoscopy units are busy. Many units have to combine the pathways of screening and elective symptomatic patients with acute and emergency procedures, yet manage the pressure of offering timely investigation, rapid throughput and ensuring an individualised, safe and comfortable experience for all patients.

\subsection{Scope of the guideline}

This document replaces the guideline of 2008. Here we offer guidance and explicit recommendations for obtaining valid consent for both elective and acute or emergency endoscopic procedures. The guideline is restricted to GI endoscopy and is intended for use by all practitioners who request or perform GI endoscopy, or are involved in the pathway of such patients. We include standards for audit, documentation and training.

This document does not include guidance on procedures performed purely for research purposes or using new or experimental procedures. Where there are variations in the legal framework around the UK these are highlighted and referenced, but it is beyond the scope of this guideline to offer a detailed review of the law and regional variations; practitioners must be familiar with the law in the area in which they work. Likewise, we do not discuss complex cases involving children under the age of 16 , where there are questions about capacity or consent and in which expert legal advice would be more appropriate.

It is acknowledged that this guideline relates only to GMC, DoH guidance and the law in the UK as it stands in 2016. Although this might change, it is felt unlikely that such changes will affect this guideline and recommendations significantly for the forseeable future.

\section{METHODS}

Members of the advisory group were selected to represent key areas within general and interventional endoscopy, nurse endoscopy, training and checklists, paediatric endoscopy, general practice, medicolegal practice and from patient representation. The composition of the advisory group was reviewed initially by the British Society of Gastroenterology (BSG) Endoscopy Committee and approved by the BSG Clinical Services and Standards Committee.

The proposed structure and content of this document was drawn up by the lead author (SME) and reviewed by all members of the advisory group. Medline and PubMed databases were searched for relevant literature and web-based searches were performed for any additional relevant documentation.

The guideline was drafted by two authors (SME and HG) and reviewed over several versions by each of the advisory group. Input from a patient representative was sought from the beginning. The completed document and recommendations were reviewed for accuracy by expert legal Counsel (KA and KMTN) before the final version was submitted for peer review.

There is a dearth of high quality clinical research on informed consent for endoscopy. Thus, recommendations were reached 
through a review of the statutory guidance from the GMC, DoH, legislation and relevant case law. These were refined to make them specifically relevant for endoscopic practice.

Each recommendation has been scored according to the GRADE system (available at http://www.gradeworkinggroup.org/ index.htm, table 1) and these guidelines conform to AGREE II principles. ${ }^{1}$ It should be noted that the strength of the recommendation in some cases reflects the implications of not following the recommendation. Evidence used in the GRADE system commonly relates to clinical trials, but the system also allows for 'evidence of some other form', which in this document commonly relates to the presence or not of statutory guidance or legislation.

A formal iterative process was pursued to achieve consensus on inclusion and grading of recommendations according to defined criteria. A completed list of recommendations, together with any supporting reference, was reviewed by each member of the guideline committee. Each member voted indicating if they were agreeable to the recommendation being included and, if so, what grading should be applied. After the voting, differences of opinion about a recommendation were discussed in a face-to-face meeting in January 2016 and either excluded or reworded until agreement was reached. The resultant list of recommendations was circulated for a final time to ensure consensus before final submission.

It was decided a priori that only recommendations for which $>80 \%$ members agreed would be included. Members were advised that where recommendations were supported by statutory guidance and failure to comply would put a practitioner's license at risk the recommendation should be strong. Where there was no statutory guidance, recommendations would be weak unless the guideline development group agreed unanimously that they should be strong.

\section{PRINCIPLES OF VALID CONSENT}

It is a general legal and ethical principle that valid consent must be obtained before starting treatment or physical investigation. This principle reflects the right of patients to determine what happens to their bodies, and is a fundamental part of good practice.
All healthcare involves decisions made by patients and those providing their care. Whatever the context in which medical decisions are made it is essential that the healthcare practitioner works in partnership with patients to ensure good care. This involves:

- listening to patients;

- respecting their views about their health;

- sharing with patients the information they want or need in order to make adequately informed decisions;

- maximising their opportunities and ability to make decisions for themselves;

- respecting the decision once made.

Patients may indicate implicitly that they give consent-that is, non-verbally (eg, by presenting their arm for their pulse to be taken), verbally or explicitly in writing. Specifically, attendance does not imply consent. The GMC stipulates that written consent is required if $^{2}$ :

- the investigation or treatment is complex or involves significant risks;

- there may be significant consequences for the patient's employment, or social or personal life;

- providing clinical care is not the primary purpose of the investigation or treatment;

- the treatment is part of a research programme or is an innovative treatment designed specifically for their benefit.

For consent to be valid, it must be given voluntarily by an appropriately informed person who has the capacity to consent to the intervention in question. This will usually be the patient or someone with parental responsibility for a child (patient under the age of 18). The other people who can give consent in law are:

- a person over 16 years (see section 6.3.2);

- a competent person under 16 years (see section 6.3.12);

- someone authorised to do so under a LPA (or welfare attorney in Scotland) (once the person for whom the LPA exists has lost capacity);

- someone who has the authority to make treatment decisions as a court-appointed deputy (or who has a guardianship order (in Scotland)).

Written consent formally confirms that an exchange of information (clinical and non-clinical) has occurred between the

Table 1 Grading of evidence and recommendations

\begin{tabular}{|c|c|c|}
\hline Grade of recommendation & Clarity of risk/benefit & Quality of supporting evidence \\
\hline $\begin{array}{l}\text { 1A. Strong recommendation. } \\
\text { High quality evidence }\end{array}$ & $\begin{array}{l}\text { Benefits clearly outweigh risk and burdens, or vice } \\
\text { versa }\end{array}$ & $\begin{array}{l}\text { Consistent evidence from well-performed randomised controlled trials or } \\
\text { overwhelming evidence of some other form. Further research is unlikely to } \\
\text { change our confidence in the estimate of benefit and risk }\end{array}$ \\
\hline $\begin{array}{l}\text { 1B. Strong recommendation. } \\
\text { Moderate quality evidence }\end{array}$ & $\begin{array}{l}\text { Benefits clearly outweigh risk and burdens, or vice } \\
\text { versa }\end{array}$ & $\begin{array}{l}\text { Evidence from randomised controlled trials with important limitations } \\
\text { (inconsistent results, methodological flaws, indirect or imprecise), or very strong } \\
\text { evidence of some other form. Further research (if performed) is likely to affect } \\
\text { our confidence in the estimate of benefit and risk and may change the estimate }\end{array}$ \\
\hline $\begin{array}{l}\text { 1C. Strong recommendation. } \\
\text { Low quality evidence }\end{array}$ & $\begin{array}{l}\text { Benefits appear to outweigh risk and burdens, or vice } \\
\text { versa }\end{array}$ & $\begin{array}{l}\text { Evidence from observational studies, unsystematic clinical experience, or from } \\
\text { randomised controlled trials with serious flaws. Any estimate of effect is } \\
\text { uncertain }\end{array}$ \\
\hline $\begin{array}{l}\text { 2A. Weak recommendation. High } \\
\text { quality evidence }\end{array}$ & Benefits closely balanced with risks and burdens & $\begin{array}{l}\text { Consistent evidence from well-performed randomised controlled trials or } \\
\text { overwhelming evidence of some other form. Further research is unlikely to } \\
\text { change our confidence in the estimate of benefit and risk }\end{array}$ \\
\hline $\begin{array}{l}\text { 2B. Weak recommendation. } \\
\text { Moderate quality evidence }\end{array}$ & $\begin{array}{l}\text { Benefits closely balanced with risks and burdens; } \\
\text { some uncertainly about the estimates of benefits, } \\
\text { risks and burdens }\end{array}$ & $\begin{array}{l}\text { Evidence from randomised controlled trials with important limitations } \\
\text { (inconsistent results, methodological flaws, indirect or imprecise), or very strong } \\
\text { evidence of some other form. Further research (if performed) is likely to affect } \\
\text { our confidence in the estimate of benefit and risk and may change the estimate }\end{array}$ \\
\hline $\begin{array}{l}\text { 2C. Weak recommendation. Low } \\
\text { quality evidence }\end{array}$ & $\begin{array}{l}\text { Uncertainty in the estimates of benefits, risks, and } \\
\text { burdens; benefits may be closely balanced with risks } \\
\text { and burdens }\end{array}$ & $\begin{array}{l}\text { Evidence from observational studies, unsystematic clinical experience, or from } \\
\text { randomised controlled trials with serious flaws. Any estimate of effect is } \\
\text { uncertain }\end{array}$ \\
\hline
\end{tabular}


patient and the healthcare professional, and that, on the basis of the information exchanged, the patient is content to proceed.

Recommendations:

- Owing to the invasive nature and potential risks, we recommend that all endoscopic procedures of the GI tract require written consent, except in an emergency. Strong recommendation, moderate quality evidence.

- Although the process of consent can be delegated, we recommend that the endoscopist performing the procedure is ultimately responsible for ensuring that the consent process is appropriate for the procedure being undertaken. Strong recommendation, moderate quality evidence.

\section{ASSESSMENT OF CAPACITY}

The law on mental capacity in the UK varies between England, Wales, Scotland and Northern Ireland. The legal framework governing treatment of people lacking capacity in the various jurisdictions is summarised in table 2. In all UK jurisdictions the law on mental capacity requires a presumption that every adult patient has the capacity to make decisions about their care and treatment and to decide whether to agree to, or refuse, any proposed medical intervention. ${ }^{3}$ A person who lacks capacity is defined as a person who is unable to make a decision for themselves because of an impairment or disturbance in the functioning of their mind or brain. It does not matter if the impairment or disturbance is permanent or temporary. A person lacks capacity if:

- they have an impairment or disturbance (eg, a disability, condition or trauma or the effect of drugs or alcohol) that affects the way their mind or brain works, and

- that impairment or disturbance means that they cannot make a specific decision at the time it needs to be made.

The principle of presumed capacity means that the patient can be considered not to have capacity only once it is shown, that they are unable to:

- understand the information needed to make a decision;

- remember that information long enough to make a decision;

- use or weigh up that information to make a decision;

- communicate their decision by whatever means (verbal, sign language or an established code such as blinking or squeezing of the hand).

Table 2 Mental capacity legal framework in UK jurisdictions

\begin{tabular}{|c|c|c|c|c|}
\hline UK territory & Legal basis & Test of capacity & $\begin{array}{l}\text { Proxy decision- } \\
\text { makers }\end{array}$ & Advance decisions \\
\hline $\begin{array}{l}\text { England and } \\
\text { Wales }^{5} 6\end{array}$ & $\begin{array}{l}\text { Mental Capacity } \\
\text { Act } 2005\end{array}$ & $\begin{array}{l}\text { A person is unable to make a decision for himself if he } \\
\text { has impairment of, or a disturbance in the functioning } \\
\text { of, the mind or brain and this means that he is unable } \\
\text { to: } \\
\text { A. understand the information relevant to the } \\
\text { decision } \\
\text { B. retain that information } \\
\text { C. use or weigh that information as part of the } \\
\text { Drocess of making the decision, or } \\
\text { communicate his decision (whether by talking, } \\
\text { using sign language or any other means) }\end{array}$ & $\begin{array}{l}\text { Lasting power of } \\
\text { attorney relevant to } \\
\text { Health and Welfare } \\
\text { Court appointed } \\
\text { deputy }\end{array}$ & $\begin{array}{l}\text { The Mental Capacity Act } 2005 \text { allows a person over } \\
18 \text { with capacity to make an advance decision to } \\
\text { refuse treatment. } \\
\text { Valid and applicable advance decisions to refuse } \\
\text { treatment must be respected. } \\
\text { If they relate to life-sustaining treatment then they } \\
\text { must be in writing, signed and witnessed. }\end{array}$ \\
\hline Scotland ${ }^{7} 8$ & $\begin{array}{l}\text { Adults with } \\
\text { Incapacity } \\
\text { (Scotland) Act } \\
2000\end{array}$ & $\begin{array}{l}\text { 'Incapable' means incapable of: } \\
\text { A. acting, or } \\
\text { B. making decisions, or } \\
\text { C. communicating decisions, or } \\
\text { D. understanding decisions, or } \\
\text { E. retaining memory of decisions } \\
\text { by reason of mental disorder or of inability to } \\
\text { communicate }\end{array}$ & $\begin{array}{l}\text { Welfare powers of } \\
\text { attorney } \\
\text { Guardian }\end{array}$ & $\begin{array}{l}\text { A competently made advance statement made } \\
\text { orally or in writing to a practitioner, solicitor or } \\
\text { other professional person would be a strong } \\
\text { indication of a patient's past wishes about medical } \\
\text { treatment but should not be viewed in isolation } \\
\text { from the surrounding circumstances. } \\
\text { An advance directive to refuse specific treatment } \\
\text { may be binding and is described as "potentially } \\
\text { binding" in the code of practice which recommends } \\
\text { that advice be sought. }\end{array}$ \\
\hline $\begin{array}{l}\text { Northern } \\
\text { Ireland }^{9}\end{array}$ & Common law & $\begin{array}{l}\text { A person is unable to make a decision for himself if he } \\
\text { has impairment of, or a disturbance in the functioning } \\
\text { of, the mind or brain and this means that he is unable } \\
\text { to: } \\
\text { A. understand the information relevant to the } \\
\text { decision } \\
\text { B. retain that information, } \\
\text { C. use or weigh that information as part of the } \\
\text { Drocess of making the decision, or } \\
\text { communicate his decision (whether by talking, } \\
\text { using sign language or any other means) }\end{array}$ & Not applicable & $\begin{array}{l}\text { An advance decision to refuse treatment may well } \\
\text { be valid under the common law. }\end{array}$ \\
\hline
\end{tabular}

\footnotetext{
1. Specific mental capacity legislation is enacted in England and Wales (The Mental Capacity Act 2005) and Scotland (Adults with Incapacity (Scotland) Act 2000). Legislation relating to mental capacity and mental health (The Mental Capacity Bill) is proceeding through the legislative process in Northern Ireland. That remains a common law jurisdiction but the principles remain very similar to those codified in the Mental Capacity Act 2005. There are, however, no provisions related to welfare attorneys.

2. Although the approach taken to adults who lack capacity by the Mental Capacity Act 2005 and the Adults with Incapacity Act 2000 is similar, there are some important differences. For example, in Scotland the 'General Power to Treat' part 5 of the Act gives a general authority to treat a patient who is incapable of consenting to the treatment in question, on the issuing of a certificate of incapacity. The general principles of the Act must be applied by the practitioner who issues such a certificate and gives treatment under it. The common law authority to treat a patient in an emergency remains in place.

3. The principle of 'best interests', though expressed differently, applies in all jurisdictions. Common law, the Mental Capacity Act 2005 and the Adults with Incapacity Act 2000 expect that people's wishes (including those expressed when the patient had capacity even if not in the form of an advance decision) should be taken in to account and that the practitioner should consult widely with those who have an interest in the patient's welfare. The holders of a relevant power of attorney that covers the treatment must of course be consulted.
} 
The Adults with Incapacity (Scotland) Act, 2000 also requires that the person can remember having made the decision. ${ }^{4}$ (http://www.legislation.gov.uk/asp/2000/4/section/1)

Capacity is 'decision specific' and so an assessment must be relevant to the intended intervention. In patients whose capacity may vary, then the assessment must be done at an appropriate time. A person must be given all appropriate help and support to maximise their ability to make decisions before it is concluded that they lack capacity.

For example, when patients may be able to make simple decisions, but not complex ones there is an added responsibility to assess their capabilities with great care. Those involved with consenting patients for endoscopic procedures must support patients to the limit of their capacity. Even where the individual lacks capacity they must be permitted and encouraged to participate as fully as possible.

It should not be assumed that a person with a mental disability (learning, dementia, mental health, brain injury) does not have the capacity to consent simply in order to expedite the procedure. If the capacity test suggests that they may have capacity, then reasonable adjustments to the consent process and timing need to be made to ensure that the person can communicate their consent.

Patients may have capacity to consent to some procedures but not to others, or may have capacity at some times but not others. A person must be assumed to have capacity unless it is established that they lack capacity.

Practical adjustments to aid the consent process may include:

- discussing treatment options at a time and in a place when the patient is best able to understand and retain the information;

- speaking to the patient or to their carers, close family members and other healthcare staff about the best ways of communicating with them, using information in a format appropriate to their circumstances, including photos, signs and symbols;

- discussing with patients the possibility of bringing a relative, carer or friend, or making a recording of the consultation, to help them remember the information discussed, or involvement of the local community disability teams as a single point of contact;

- offering patients a record of the discussion and any decisions made during a consultation (including relevant information about why the decision was made) where there is a lot of information to remember, or the decision will have a significant effect on their life or care.

Where there is doubt about a patient's capacity to consent, the procedure should be delayed, unless unsafe to do so, and advice sought from other colleagues, including a psychiatric team when necessary.

\subsection{Further information}

- The Mental Capacity Act Code of Practice (2007), available at https://www.gov.uk/government/publications/mental-capacityact-code-of-practice, explains how the Act will operate day to day and offers examples of best practice to carers and practitioners. A number of assessment tool kits are also available to guide health professionals through the assessment process:

- The British Medical Association Mental Capacity Toolkit covers topics such as how to assess capacity, the basic principles of the Act, advance refusals of treatment, research and LPAs; available at http://bma.org.uk/advice/employment/ ethics/mental-capacity-tool-kit
- A toolkit to assess capacity is available from the GMC on http://www.gmc-uk.org/Mental_Capacity_flowchart

- Further information and resources are provided through the Mental Health Foundation on https://www.mentalhealth.org. uk/a-to-z/m/mental-capacity

- OPG603 Office of the Public Guardian (2009). Making decisions. A guide for people who work in health and social care: the mental capacity Act. 4th edition; available at https://www.gov.uk/government/uploads/system/uploads/ attachment_data/file/348440/OPG603-Health-care-workersMCA-decisions.pdf

Recommendations:

- We recommend that the endoscopist performing the procedure ensures that the patient has capacity to consent to the procedure. If capacity to consent appears to have changed since consent was first obtained then reassessment is required. Delaying the procedure to allow further adjustments or the opportunity to regain capacity may be appropriate, but a decision to proceed based on 'best interests' (see section 7, 'Patients considered not to have capacity') can also be considered if it is likely that capacity will not be recovered. Strong recommendation, moderate quality evidence.

\section{PATIENTS CONSIDERED TO HAVE CAPACITY 6.1 Provision of information}

\subsubsection{General principles: outpatients}

Clear, accurate information about any proposed investigation or treatment, including alternative available treatments and the option of having no treatment, presented in a way that patients can understand, can help them to make informed decisions. The amount of information that should be shared with patients will depend on the procedure, the individual patient and what they want or need to know. Information about risk must be given in a balanced way. Bias should be avoided, and the expected benefits as well as the potential burdens and risks of any proposed procedure should be explained.

The aim is to provide information so that patients can select for themselves how much detail they want to acquaint themselves with. The patient should be able to derive an understanding of what is about to happen, when, where and why it will occur.

As part of the consent process and to allow the patient to make an informed decision, written information should be provided in advance of the procedure with sufficient time for the patient to read, evaluate and seek further information if required.

Information about the procedure should be in plain language that the patient can understand, in a font or format they can read and available in languages other than English. Although it may not be possible to provide written information in all languages or formats, local communities should be contacted to identify those languages that are common. Information leaflets should be proof read by lay people or patient representatives to ensure that they meet the needs of the local population.

It is important to emphasise that written information is only part of the consent process. All clinicians involved in the patient pathway have a responsibility to provide verbal information and answer questions, regardless of the provision of written leaflets. At a minimum, verbal information should be provided by the clinician at the time he/she recommends the procedure with the opportunity to ask further questions once the patient has had the chance to read the written information.

When written information is not available in an appropriate language or format for patients, it is essential to ensure that 
verbal information has been offered through an interpreter before the patient attends the endoscopy unit and on the day of the procedure. Usually, this would be at the time of an outpatient appointment.

\subsubsection{Provision of information by post}

Patients may be referred by their general practitioners directly for endoscopic investigation. While general practitioners referring patients can be expected to understand the nature of the investigation, it cannot be assumed that they are sufficiently trained to discuss all the relevant risks and benefits with the patient. Thus, the organisation receiving the referral must put in place pathways to ensure that the referral is appropriate and the patient is adequately informed.

Previously, this process was termed 'postal consent'. Although we endorse the provision of information to patients by post, we no longer recommend the use of this term as it implies that the consent process has been completed before the patient attends for the procedure. Provision of information ahead of the procedure by a number of means, including post, is recommended, particularly for direct access procedures, but patients must be given the opportunity for discussion either before or on the day of the procedure with confirmation of their consent by a person qualified to take consent on the day of attending.

Referrals may be for 'direct access' investigation, in which the GP is referring for the test only, on a suspected cancer pathway ('straight to test') or before an outpatient appointment ('test first'). These pathways and terminology will vary between hospitals but usually refer only to diagnostic procedures, most commonly upper GI endoscopy or flexible sigmoidoscopy and sometimes colonoscopy. However, where such a process is implemented for higher risk or more complex procedures, an opportunity to discuss the procedure either by telephone or face to face should be made available in advance of the day as a minimum standard.

The GMC states that before beginning treatment, you or a member of the healthcare team should check that the patient still wants to go ahead and you must respond to any new or repeated concerns or questions they raise. This is particularly relevant to postal provision of information, which might have been sent some weeks previously and the patient might not have discussed the procedure with a trained practitioner.

As patients referred straight to test will not usually have had the opportunity for discussion with an endoscopist before the procedure, the organisation must ensure that the procedure is appropriate and the patient adequately informed before arrival. Furthermore, for patients on some pathways (eg, suspected cancer) the tight timescales may mean that the post cannot be relied upon to provide the information before the appointment date, and under these circumstances alternative arrangements must be made. This might include giving patients the opportunity to discuss the procedure on the phone with a trained practitioner, collect the information leaflet in person before attending, emailing information or providing information 'online'.

\subsubsection{General principles: inpatients}

The principles for provision of information relating to inpatients requiring urgent or emergency endoscopy are the same as those for outpatients. However, patients in hospital may be referred by teams who may not be fully familiar with the risks, benefits or alternatives to endoscopy. There is usually a greater urgency to perform the procedure, both for clinical and efficiency reasons. As a rule, patients will be at higher risk, with greater degrees of comorbidity than outpatients. Finally, inpatient procedures are usually more complex and interventional. This combination of factors means there is a higher risk, which must be reflected in the consent process and provision of information.

All inpatients referred for endoscopy, whether diagnostic or therapeutic, must have the referral reviewed for appropriateness by a clinician trained in the indications for that procedure. In addition, all patients who have an inpatient endoscopy, where practical, must have written information provided to them in a format they can read and understand before they leave the ward for the procedure and an opportunity to discuss that information with an appropriately trained person.

In this context, 'appropriately trained' refers to a person who is trained to perform the procedure or a person to whom this task has been delegated who is suitably trained, has sufficient knowledge of the proposed investigation or treatment and understands the risks involved. ${ }^{2}$

Best practice is that all patients referred for endoscopy should give their consent on the ward. Although this may not always be practicable, and clinical urgency has to be taken into consideration, information must be provided on the ward no later than the time at which the decision to proceed with the procedure was made. Sufficient time must be given for the patient to read, assimilate the information and ask questions. Apart from clinical emergencies, it is not acceptable for a patient to attend an endoscopy unit without first having been provided with written information, and given time to read and ask questions about it on the ward.

Where appropriate written information cannot be provided owing to language barriers or the unique nature of the procedure, verbal information must be provided by appropriately trained clinicians, assisted as necessary by interpreters, before the patient leaves the ward.

As with outpatient procedures, it is particularly important to emphasise that all clinical staff involved in that patient's care have a duty to provide information and support the consent process to the level of their training, even if they are not specifically trained to obtain consent for that procedure. This may involve simply providing written information or answering questions, but where the clinician cannot answer a patient's query they are duty bound to ensure that the patient is given access to someone who can.

\subsubsection{What information should be provided?}

In general, written information for an endoscopic procedure should include the following details:

- the process of the procedure (eg, the appointment, hospital, endoscopy suite, management of drugs and key medical conditions, for example, diabetes, arrangements on arrival and subsequent discharge, and contact numbers);

- any preparation required and associated risks, such as fasting and bowel preparation;

- the procedure itself and necessary aftercare;

- options and expectations in relation to sedation and analgesia;

- benefits, risks (complications and side effects) and limitations of the procedure;

- possible alternatives to the proposed intervention in the case of treatment failure, including the benefits and risks of these alternative treatments;

- the taking and retention of tissue samples; 
- the taking of a photographic or video record and possible secondary uses of anonymised records, such as for teaching or assessment of health professionals;

- skilled supervision and presence of any trainees and the right of the patient to refuse having a trainee perform the procedure without prejudice to their treatment;

- use of any experimental technique;

- contact details in case further information is required by the patient.

Patients must be offered as much information as they reasonably need to make their decision. It must be open and honest and in a form they can understand, with adequate time allowed. Information must be given before preparation for the procedure starts-for example, fasting and/or bowel preparation, and patients must be carefully assessed before safe administration of any bowel preparation.

It is important to ensure that the written information has been understood, particularly any material risks, and that the patient is given the opportunity to ask questions or raise concerns and have these answered in a full, open and honest manner. Any concerns expressed by the patient, even if not in the form of questions, should also be dealt with in the same way.

Possible adverse outcomes from the proposed procedures must be presented, including the possibility that the procedure is not performed or fails to achieve the desired aim.

$\mathrm{DoH}$ guidance is that a person should be advised of any material, significant or unavoidable risks in the proposed treatment, even if small; any alternatives to it; and the risks incurred by doing nothing, to reflect the Chester versus Afshar judgement. ${ }^{10}$ A Court of Appeal judgement stated that it will normally be the responsibility of the doctor to inform a patient of "a significant risk which would affect the judgement of a reasonable patient". Further clarity has been provided from the Supreme Court in Montgomery versus Lanarkshire Health Board in 2015 (UKSC_2013_0136_Judgment) in which it is stated $(\text { para } 87)^{11}$ :

\footnotetext{
"The doctor is therefore under a duty to take reasonable care to ensure that the patient is aware of any material risks involved in any recommended treatment, and of any reasonable alternative or variant treatments. The test of materiality is whether, in the circumstances of the particular case, a reasonable person in the patient's position would be likely to attach significance to the risk, or the doctor is or should reasonably be aware that the particular patient would be likely to attach significance to it"
}

The test of materiality is procedure-, circumstance- and patient-specific. The test must be patient-centred, since the risk that can influence a patient's decision can vary from one patient to the next and requires careful judgement and individual discussion. Thus, it is beyond the scope of this document to describe in detail the information in relation to risks, benefits or alternatives that should be provided for specific endoscopic procedures. Similarly, it is not possible to state in this guideline whether specific risks should be mentioned or in numerical terms what level of risk should be described.

In general, however, you must tell patients if the procedure might result in a serious adverse outcome, even if the likelihood is very small, and mention less serious side effects or complications if frequent. Any risk that is likely to influence the decision of a patient should be included. It is important that in meeting these requirements, the patient is not overwhelmed with excessive information, such that they are unable to evaluate the material risks and benefits.
Notwithstanding these comments, diagnostic endoscopy remains overall a safe procedure. Written information leaflets provide a minimum dataset that we pass onto patients, but if an individual's risk is higher owing to frailty or comorbidity then this must be discussed verbally and/or additional written information provided to reflect this risk and that information documented in the case notes.

As a final point, if a clinician decides that it would be detrimental to the health of the patient to make a particular disclosure then that disclosure need not be made. However, all practitioners should think carefully before not sharing information with a patient and be able to justify their decision. In the case of Montogomery it is stated (para 91):

\begin{abstract}
"the therapeutic exception should not be abused. It is a limited exception to the general principle that the patient should make the decision whether to undergo a proposed course of treatment: it is not intended to subvert that principle by enabling the doctor to prevent the patient from making an informed choice where she is liable to make a choice which the doctor considers to be contrary to her best interests."
\end{abstract}

\subsubsection{Patients who decline information}

No one else can make a decision on behalf of an adult who has capacity. If a patient asks you to make decisions on their behalf or wants to leave decisions to a relative, partner, friend, carer or another person close to them, you should explain that it is still important that they understand the options open to them, and what the treatment will involve. If they do not want this information, you should try to find out why.

If, after discussion, a patient still does not want to know in detail about their condition or the treatment, you should respect their wishes, as far as possible. But you must still give them the information they need in order to give their consent to a proposed investigation or treatment. This is likely to include what the investigation or treatment aims to achieve and what it will involve-for example, whether the procedure is invasive; what level of pain or discomfort they might experience, and what can be done to minimise it; anything they should do to prepare for the investigation or treatment; and if it involves any significant risks.

If a patient insists that they do not want even this basic information, you must explain the potential consequences of them not having it, particularly if it might mean that their consent is not valid. You must record the fact that the patient has declined this information. You must also make it clear that they can change their mind and have more information at any time.

Recommendations:

- For all patients, we recommend that information should be provided in a format that they can understand about the expected benefits as well as the potential burdens and risks and alternatives of any proposed endoscopic procedure. Strong recommendation, moderate quality evidence.

- For outpatient elective procedures, we suggest that verbal and/or written information should be provided by the clinician recommending the endoscopy at the time of the consultation and this should be documented in the clinical notes. Weak recommendation, moderate quality evidence.

- For outpatient procedures, we recommend that written information should be provided in advance of the procedure with sufficient time for the patient to read, evaluate and seek further information if required. Strong recommendation, low quality evidence.

- We recommend that endoscopy units retain information leaflets that pertain to all standard endoscopic procedures 
performed regularly within that unit. They must retain a $\log$ of these information leaflets, when last updated and by whom, and each leaflet must be reviewed annually by endoscopy staff and incorporate questions frequently asked by patients. Strong recommendation, low quality evidence.

- We suggest that information leaflets should be available in languages common to the local population and should be reviewed by lay people. Weak recommendation, low quality evidence.

- Where procedure specific information leaflets are not available (eg, for infrequent or specialist procedures) we recommend that the patient has the opportunity to discuss that procedure before the appointment with the endoscopist (or a delegated person), either face to face or by telephone, with the discussion clearly documented in the medical records. Strong recommendation, low quality evidence.

- Written information provides a minimum dataset but if an individual's risk is higher owing to frailty or comorbidity, we recommend that this be discussed verbally and/or additional written information provided to reflect this risk and that information documented in the case notes. Strong recommendation, moderate quality evidence.

- We recommend that all patients are given the opportunity to express their individual concerns, and consent should reflect that discussion. Strong recommendation, moderate quality evidence.

- For inpatients, we recommend that, where available, written information is provided in an appropriate format to the patient before they leave the ward for the procedure, allowing sufficient time for the information to be read and questions to be asked. Where ward staff cannot answer the questions they must ensure that the patient is given access to someone who can. Strong recommendation, moderate quality evidence.

- For patients who decline information, we recommend that the minimum information should include the aims of the proposed investigation or treatment, the expected level of pain or discomfort and steps taken to minimise it. In addition, the level of risk related to the procedure that the patient wishes to know (or not) should be ascertained and recorded. Strong recommendation, moderate quality evidence.

- We recommend that it is ensured that the written information has been understood with particular reference to any material risks and that the patient is given the opportunity to ask questions or raise concerns and have these answered in a full, open and honest manner. Any concerns expressed by the patient, even if not in the form of questions, should also be dealt with in the same way. Strong recommendation, moderate quality evidence.

- For direct to test procedures, we recommend that the organisation receiving the referral puts in place pathways to ensure that the referral is appropriate and the patient adequately informed. Strong recommendation, low quality evidence.

\subsection{Confirmation of consent}

\subsubsection{Who can seek consent?}

The GMC states that "if you are the doctor undertaking an investigation or providing treatment, it is your responsibility to discuss it with the patient. If this is not practical, you can delegate the responsibility to someone else, provided you make sure that the person you delegate to:

- is suitably trained and qualified;

- has sufficient knowledge of the proposed investigation or treatment and understands the risks involved;
- understands, and agrees to act in accordance with this booklet.

If you delegate, you are still responsible for making sure that the patient has been given enough time and information to make an informed decision, and has given their consent, before you start any investigation or treatment" (ref 2, para 26).

In endoscopy units, this means that the endoscopist performing the procedure must:

- verify that the patient has the capacity to make the decision in question and either,

- obtain consent themselves or

- verify and document that the consent has been legitimately obtained by someone who is capable of doing so;

- reassess capacity if it appears that the status has changed.

This means that the ultimate responsibility for ensuring that appropriate consent has been obtained for the procedure being undertaken is with the endoscopist, who should confirm this before the patient enters the room. If the procedure is being performed by a trainee under supervision, the responsibility for obtaining consent can be delegated to the trainee, but the ultimate responsibility remains with the supervising endoscopist.

Endoscopy nurses may take consent ('nurse-led consent') provided that they have been trained to do so (see section 9.4). It is recommended that their training is documented in their portfolio and is updated and revalidated annually as part of the appraisal process.

In practice, it is likely that delegation of consent to non-endoscopists (either junior doctors or nurses) may be possible for high volume, low risk procedures, such as diagnostic upper endoscopy, flexible sigmoidoscopy or colonoscopy but is unlikely to be appropriate for procedures that may or will involve more complex therapeutic interventions such as dilatation, polypectomy or endoscopic retrograde cholangiopancreatography.

Whatever arrangements are adopted locally should be recorded within the Trust Consent Policy, and be formally approved under local governance procedures. This documentation should be readily accessible to any external inspection agency.

\subsubsection{The consent process}

The seeking and giving of consent should be a process, rather than a one-off event. It is good practice, where possible, to seek the person's consent to the proposed procedure well in advance, when there is time to respond to questions and provide adequate information. Endoscopists should then check, before the procedure starts, that the person still consents. This is particularly relevant to inpatients for the reasons alluded to above.

Although consent is not necessarily time-limited, if consent has been obtained a significant time before undertaking the intervention, it is good practice to confirm that the person who has given consent (assuming that they retain capacity) still wishes the intervention to proceed, even if no new information needs to be provided or further questions answered.

DoH guidance is that "if a person is not asked to signify their consent until just before the procedure is due to start, at a time when they may be feeling particularly vulnerable, there may be real doubt as to its validity" (ref 5, para 31). Although this does not specifically state that consent for an endoscopic procedure should be sought before entering the endoscopy procedure room, the principles of this guidance means that such practice would be difficult to defend should it be called into question.

Thus, the final signature confirming consent, or verification of a previously signed consent form (eg, if posted to the patient or for ward inpatients), should occur outside the endoscopy room, 
in a calm and private environment where the patient does not feel coerced into making a decision by the immediacy of their surroundings.

For inpatients, ideally the consent form will be signed by the patient and countersigned by an appropriately trained individual on the ward (as described in section 6.2.1) before attending the endoscopy department. However, it is recognised that this may not always be possible for complex interventional procedures. Under which circumstances, so long as the requirements for adequate provision of information (section 6.1.3), and for signing the form in a calm and private environment are met as above, then it is acceptable that the consent form for an inpatient procedure be signed in the endoscopy unit but outside the procedure room.

Recommendations:

- Consent should be obtained by the endoscopist or delegated to a suitably trained individual. Strong recommendation, moderate quality evidence.

- The formal consent process should be completed before entry into the procedure room. Final validation of that process should occur before the procedure starting. Strong recommendation, low quality evidence.

\subsubsection{The consent form}

The contents of consent forms are for local services to determine. Each service will have developed forms that correspond to the now archived Department of Health Guidance. Updated guidance on how to amend these forms in the light of recent legislative changes is available at https:/www.gov.uk/government/ uploads/system/uploads/attachment_data/file/138297/dh_103652. pdf

As a general principle, it is advisable for services to retain consent forms for patients with capacity that are specific to high volume procedures such as diagnostic endoscopy and colonoscopy that include standardised risks and benefits. However, where such forms do not correspond to the specific procedure being undertaken, the form must be amended before the patient signs it, or a blank form completed.

Consent forms should name the procedure in clear terms understandable to the patient, avoid abbreviations and complex medical jargon and describe the material risks and benefits and alternative procedures as well as any additional procedures (such as biopsies) and procedures the patient might not want. The name and grade of the consenting practitioner(s) should be legible, the form should state if trainees may be involved, and there should be a space for an interpreter to sign the form where appropriate. Patients must be given sufficient time to read and complete the consent form and should be offered a copy of the completed form.

\subsubsection{Consent as integral part of care pathway in endoscopy}

Given the high volume and increasing therapeutic nature of endoscopy in many units, the complexity and risk of endoscopic procedures and the implications for the patient and endoscopist of an incomplete or inappropriate consent process, endoscopy departments must put in place measures to ensure consent is appropriate and complete (relevant to the clinical circumstances) for all patients attending for a procedure.

Ample evidence now exists in surgery that adoption of the WHO safer surgery checklist in the operating theatre reduces the opportunity for error. ${ }^{12}$ Adaptations of such checklists are being proactively adopted by many endoscopy units. ${ }^{13}$ Although there is no proof of similar efficacy of such checklists in endoscopy units to the theatre environment nor of the ideal format, early adopters have confirmed that such adapted checklists reduce the opportunity for error, facilitate whole team communication and allow patient involvement-for example, through reconfirmation of consent. Examples of endoscopy-specific checklists include elements such as positive patient identification and procedure and equipment related checks. As part of this process endoscopy units should also include in the checklist final confirmation that the consent form has been completed (barring exceptional (eg, emergency) circumstances) for the correct patient and procedure. This process has now been enshrined in the National Safety Standards for Invasive Procedures published by NHS England in $2015 .{ }^{14}$

Recommendation:

- Endoscopy units should incorporate a check within their patient pathway booklet or an adapted WHO safer surgery checklist that adequate and valid consent has been obtained before starting the procedure. Strong recommendation, moderate quality evidence.

\subsection{Special circumstances}

\subsubsection{Consent for surveillance procedures}

Many patients have surveillance endoscopic procedures planned some months or years in advance without need for medical review in between. Examples would be follow-up for Barrett's oesophagus or colonic adenomas. Many hospitals now put patients on a system whereby they are automatically recalled for endoscopy or colonoscopy some years after the previous examination.

It is possible for the patient to consent in advance for such procedures. The DoH states that when a person gives valid consent to an intervention, in general that consent remains valid for an indefinite duration, unless it is withdrawn by the person. ${ }^{5}$ However, because a patient has agreed to a surveillance programme does not imply that their consent is valid for all subsequent procedures and consent should be sought in advance of all procedures in the standard way.

Furthermore, if new information becomes available about the proposed procedure between the times the patient agreed to surveillance and when the procedure is planned to be undertaken, a member of the healthcare team should inform the patient and reconfirm their agreement to surveillance. Specifically, if the guidelines in relation to surveillance intervals or risk of disease change between procedures, a patient should be informed so that they can consent (or not) in light of this new information.

Similarly, it is necessary to check whether the patient's condition or medication has changed significantly before any surveillance procedure as, if it has, then it will be necessary to discuss the pros and cons of surveillance again, as the likely benefits and/or risks of the intervention might also have changed.

Although consent can be obtained a significant time before undertaking the intervention, it is good practice to confirm that the person who has given consent (assuming that they retain capacity) still wishes to proceed, even if no new information needs to be provided or further questions answered.

Recommendations:

- We recommend that consent should be sought in advance of all surveillance endoscopic procedures in the standard way. Strong recommendation, low quality evidence.

- If new information becomes available in relation to surveillance intervals or risk of disease, or if the patient's condition has changed, we recommend that the patient's agreement to remain in a surveillance programme should be reconfirmed. Strong recommendation, moderate quality evidence.

\subsubsection{Children}

Guidance on consent for children (aged $<18$ years) is provided by the GMC both in its 2008 guidance on consent ${ }^{2}$ but in 
greater detail in its 2007 document ' $0-18$ years: guidance for all doctors $^{15}$ and by the DoH 2009 second edition advice on consent. $^{5}$

Significant regional variations in child law exist within the UK and in other parts of the world; the variations in devolved UK countries are summarised in table 3 but it is beyond the scope of an endoscopy-related document to describe all the variations and complexities of child law on consent.

The capacity to consent for endoscopy depends more on the young person's ability to understand and weigh up options than on age. A young person aged 16 or 17 is presumed to be capable of consenting to their own medical treatment, and any ancillary procedures involved in that treatment, such as an anaesthetic. ${ }^{16}$ In order to establish whether a young person has the requisite capacity to consent to a proposed intervention, the same criteria as for adults should be used unless a decision cannot be made for some reason other than a disturbance in the functioning of the mind or brain-for example, being overwhelmed by the magnitude of the decision, in which case legal advice should be sought. If the 16 or 17 -year-old is capable of giving valid consent then it is not legally necessary to obtain the authority of a person with parental responsibility for that person, though often the young person may welcome the involvement of family in decision-making.

A young person under 16 may also have the capacity to consent, depending on their maturity and ability to understand what is involved. In English law this is based on the case of Gillick, in which the court held that children who have sufficient understanding and intelligence to enable them to understand fully what is involved in a proposed intervention will also have the capacity to consent to that intervention. The concept of Gillick competence is said to reflect a child's increasing maturity. However, the understanding required for different procedures will vary considerably and the child's capacity to consent should therefore be assessed carefully in relation to each decision, and age-appropriate material should be available to assist this process. The principles of Gillick competence are maintained in other nations in the UK, though the legislative background is different (table 3).

If, after careful assessment, a child aged $<16$ years is deemed competent and able to give voluntary consent, that consent will be valid and additional consent by a person with parental responsibility will not be required. However, because competence in a child younger than 16 years is variable, complex and relates to the maturity of the child, it should be assessed, for all but the simplest situations, only by practitioners trained to do so.

Where a child under the age of 16 lacks capacity to consent, consent can be given on their behalf by any one person with parental responsibility. In this circumstance it is good practice to consider asking the child to counter-sign the form with their 'assent' to undergo the procedure.

It is usually sufficient to have consent from one parent but if parents cannot agree and disputes cannot be resolved informally, you should seek legal advice about how to proceed. Those authorising treatment on behalf of children and young people must themselves have the capacity to consent to the intervention in question, be acting voluntarily and be appropriately informed. The power to consent must be exercised according to the 'welfare principle': that the child's 'welfare' or 'best interests' must be paramount. The approach to a child who is deemed competent but refuses treatment is complex. Guidance from the GMC states:

'Parents cannot override the competent consent of a young person to treatment that you consider is in their best interests. But you can rely on parental consent when a child lacks the capacity to consent. In Scotland parents cannot authorise treatment a competent young person has refused.

In England, Wales and Northern Ireland, the law on parents overriding young people's competent refusal is complex. You should seek legal advice if you think treatment is in the best interests of a competent young person who refuses.' (ref 15, para 31)

Given the complexity of the law, the safest course of action for a practitioner faced with a situation where refusal of an endoscopic procedure would result in risk of serious harm to the child, or where any conflict exists, would be to seek advice from the legal department of their employer or medical defence organisation.

In summary, children and young people should be encouraged to involve their parents in all decisions. Young people aged over 16 can consent to endoscopic procedures if they have capacity. Children aged less than 16 years may give assent for a procedure and if considered competent may give consent. If not considered competent they may still give assent but parental authority should be sought. In any situation where doubt exists and

Table 3 Regional variations in child law in relation to consent

\begin{tabular}{|c|c|c|}
\hline UK territory & $16-18$ year olds & Children under 16 \\
\hline $\begin{array}{l}\text { England and } \\
\text { Wales }\end{array}$ & $\begin{array}{l}\text { Family Law Reform Act } 1969 \text { provides that a person over } 16 \text { is presumed } \\
\text { to have capacity to consent to treatment }\end{array}$ & $\begin{array}{l}\text { Gillick } v \text { West Norfolk and Wisbech AHA [1986] AC } 112 \\
\text { Children can give their own consent to treatment if they have sufficient maturity } \\
\text { and understanding of the proposed intervention }\end{array}$ \\
\hline Scotland & $\begin{array}{l}\text { Age of Legal Capacity Scotland Act provides that those over } 16 \text { are } \\
\text { presumed to have capacity to consent to treatment }\end{array}$ & $\begin{array}{l}\text { Section 2(4) Age of Legal Capacity (Scotland) Act } 1991 \\
\text { Allows a child under } 16 \text { years old to consent to medical, dental or surgical } \\
\text { treatment provided that the medical practitioner attending him considers that he } \\
\text { is capable of understanding the nature and possible consequences of the } \\
\text { procedure or treatment }\end{array}$ \\
\hline $\begin{array}{l}\text { Northern } \\
\text { Ireland }\end{array}$ & $\begin{array}{l}\text { Age of Majority Act } 1969 \text { (Northern Ireland) provides that a minor who } \\
\text { has reached the age of } 16 \text { years can consent to surgical, medical or } \\
\text { dental treatment }\end{array}$ & $\begin{array}{l}\text { Gillick } v \text { West Norfolk and Wisbech AHA [1986] AC } 112 \\
\text { Children can give their own consent to treatment if they have sufficient maturity } \\
\text { and understanding of the proposed intervention }\end{array}$ \\
\hline \multicolumn{3}{|c|}{$\begin{array}{l}\text { 1. In all jurisdictions a person over } 16 \text { is presumed to have the capacity to consent to treatment-this refers to medical treatment and not to research. } \\
\text { 2. In all jurisdictions a child who has sufficient maturity to understand the purpose, risks and nature of the proposed treatment can provide their own consent. } \\
\text { 3. Neither the Age of Majority Act (Northern Ireland) nor the Family Law Reform Act } 1969 \text { interferes with the right of a person with parental responsibility for a child to authorise } \\
\text { treatment. However, the law is complex in relation to the refusal of treatment by a competent minor in circumstances where there is a significant risk to health and either those with } \\
\text { parental responsibility or those looking after the patient believe that treatment is necessary. Specific legal advice should be sought in those circumstances. } \\
\text { 4. In Scotland the case of Houston (Applicant) } 1996 \text { SCLR } 943 \text { sets authority for the concept that parental authority cannot over-ride the refusal of a competent minor. However, the } \\
\text { court might still authorise treatment in some cases and specific advice should be sought in the relevant circumstances. }\end{array}$} \\
\hline
\end{tabular}


refusal of an endoscopic procedure could result in serious harm to the child, then legal advice should be sought.

Recommendations:

- Young people aged 16-18 years are presumed to have capacity to consent to endoscopy and related procedures. We recommend that endoscopists competent to perform the procedure in adults should apply similar principles in young people over 16. Strong recommendation, moderate quality evidence.

- Competent children aged $<16$ years can consent to endoscopy but we recommend that competence should be confirmed by practitioners trained and experienced in doing so. Strong recommendation, low quality evidence.

- Where any doubt or conflict exists about consenting to endoscopy in a young person ( $<18$ years) or if the young patient refuses treatment we recommend that expert legal advice is sought. Strong recommendation, moderate quality evidence.

\subsubsection{Emergency endoscopy}

Provision of information and obtaining written consent for inpatient endoscopy procedures is outlined in section 6.1.3. However, in an emergency it may not be possible to obtain written consent and then it is reasonable to rely on verbal consent but it is still important to give the patient the information they need to make a decision and this should be recorded in their medical records.

For a patient requiring endoscopy in a life-threatening situation, such as severe GI haemorrhage, it is important to discuss with them, before sedation, the extent of treatment that may become necessary during the emergency and to which they do or do not consent, including, for example, interventional radiology, surgery or intensive care.

In an emergency, when a patient's wishes cannot be obtained, you can treat them without their consent, provided that the treatment is immediately necessary to save their life or to prevent a serious deterioration of their condition and that an advanced directive has not been provided (section 7, 'Patients considered not to have capacity') (ref 2, para 79). When written or verbal consent cannot be obtained and endoscopy is considered to be in the patient's best interests, the action taken must be the least restrictive of the patient's future options but still compatible with the purpose of the intervention.

Recommendations:

- In an emergency, full compliance with written consent may not be possible and in these circumstances we recommend that verbal consent is used but must be fully documented in the medical notes. Strong recommendation, moderate quality evidence.

- Where written or verbal consent cannot be obtained in an emergency we recommend that the action taken must be the least restrictive of the patient's future options. Strong recommendation, moderate quality evidence.

\subsubsection{Unexpected findings at endoscopy}

It is important that consent and provision of information are as comprehensive as possible before the procedure, and should include all possible outcomes and additional procedures that might be required to fulfil the primary objective of the endoscopy. However, even with such comprehensive discussions, unexpected findings are occasionally encountered at endoscopy, requiring further treatment that has not been discussed. Examples include (but are not limited to) dilatation of unexpected strictures or removal of large polyps.
Under these circumstances the endoscopist must decide whether the consent for the procedure and the level of risk and complications described before starting include the treatment of these findings. It is unlikely that any discussion during the procedure, whether the patient is sedated or not, would fulfil the principles of valid consent and endoscopists should not extend the scope of prior consent unless there is immediate risk of significant harm or death. If the consent does not cover the additional procedure, and there is no immediate risk, the procedure should be completed as far as is possible and a further procedure arranged after further discussion with the patient.

There may exceptionally be circumstances in which the objectives cannot be met without performing additional procedures and failure to do so would expose the patient to immediate risk of harm. In this situation, it is reasonable to proceed under the principles of best interests.

Recommendation:

Endoscopists should be careful to define the extent of consent before the procedure and consent should be taken for treatments that can reasonably be expected to occur during the procedure. The scope of that consent should not be exceeded unless failure to intervene would cause immediate harm. Strong recommendation, low quality evidence.

\section{PATIENTS CONSIDERED NOT TO HAVE CAPACITY}

The Mental Capacity Act 2005 (MCA) covers people in England and Wales who cannot make some or all decisions for themselves. ${ }^{3}$ In Scotland, the Adults with Incapacity (Scotland) Act 2000 provides ways to help safeguard the welfare of people aged 16 and over who lack the capacity to take some or all decisions for themselves. ${ }^{4}$ There is no primary legislation on capacity covering Northern Ireland. Decisions about medical treatment and care when people lack capacity must be made in accordance with the common law, which requires decisions to be made in a person's best interests.

The general principles of the MCA (England and Wales), which are similar in the Scottish Act are:

- A person who is over the age of 18 must be assumed to have capacity unless it is established that he/she lacks capacity.

- A person is not to be treated as unable to make a decision unless all practicable steps to help him/her to do so have been taken without success.

- A person is not to be treated as unable to make a decision merely because he/she makes an unwise decision.

- An act done, or decision made, under this Act for or on behalf of a person who lacks capacity must be done, or made, in his/her best interests.

- Before the act is done, or the decision is made, regard must be had to whether the purpose for which it is needed can be as effectively achieved in a way that is less restrictive of the person's rights and freedom of action.

No-one can give consent on behalf of an adult lacking capacity unless nominated within a valid personal welfare Lasting Power of Attorney (LPA), a Court of Protection appointed deputy or as a named person (in care proceedings), in which case you must consult them. The LPA may specify limits to the attorney's authority and whether or not the attorney has the authority to make decisions about life-sustaining treatment. It may be important to read the LPA, if available, to understand the extent of the attorney's power. In these cases it is the attorney or advocate who must, in giving or withholding consent, act in the best interests of the patient. It should be noted, however, that a LPA can only consent on behalf of a patient once the patient has lost capacity to consent for that procedure at that time. 
In the absence of a personal welfare LPA, but where there is a legal family or guardians, you may treat a patient lacking capacity if the treatment would be in the patient's best interests. However, 'best interests' is a concept that goes wider than 'best medical interests'. It includes factors such as the wishes and beliefs of the patient when competent, their current wishes, their general well-being and their spiritual and religious welfare. People close to the patient may be able to give you information on some or all of these factors.

If a person deemed to lack capacity has clearly indicated in the past, while competent, an intention to refuse treatment in certain circumstances (an 'advance decision', 'living will' or an 'advance directive'), and those circumstances arise, you must abide by that decision if it is valid and applicable.

Advance decisions to refuse life-sustaining treatment must comply with specific requirements to be valid. They must be made in writing and contain a specific statement that explicitly confirms that the advance decision applies even if their life is at risk. The decision must be signed by the patient, (or by someone else appointed by them) in the presence of a witness, who must also sign the document.

The Mental Capacity Act 2005 protects a health professional from liability for treating or continuing to treat a person in the person's best interests if they are not satisfied that an advance decision exists which is valid and applicable. The Act also protects healthcare professionals from liability for the consequences of withholding or withdrawing a treatment if at the time they reasonably believe that there is a valid and applicable advance decision. If there is doubt or disagreement about an advance decision's existence, validity or applicability, the case should be referred to the Court of Protection.

Standard model consent form 4 should be used to document a 'best interest' consent. The key points to consider are that you:

- make the care of your patient your first concern; decisions made must always be in the patient's best interests;

- treat patients as individuals and respect their dignity;

- encourage and support patients to be involved in decisions about their treatment and care;

- treat patients with respect and do not allow your personal views or assumptions about patients' lifestyle, beliefs, views or quality of life to adversely affect the decisions you make about their treatment and care;

- make sure that anything done for, or on behalf of, people without capacity is the least restrictive of their basic rights and freedoms.

In reaching a decision about any proposed investigation or treatment, you must also consider:

- whether the patient's loss of capacity is temporary or permanent and allow for fluctuations;

- what options for treatment are clinically indicated and which option (including the option not to treat) would be least restrictive of the patient's future choices;

- what you and the rest of the healthcare team know about the patient's wishes, feelings, beliefs and values, and any evidence of the patient's previously expressed preferences, such as an advance statement or decisions;

- the views of the patient's partner, family, carer or other person who has an interest in the patient's welfare;

- the views of anyone else that the patient asks you to consult, or in the absence of friends or relatives the IMCA service where the intervention amounts to 'serious medical treatment" ${ }^{17}$;

- what information is relevant to the decision that has to be taken, following guidance in the DoH document 'Confidentiality: NHS Code of Practice'. ${ }^{18}$
The Mental Capacity Act has, since 2007 in England and Wales, introduced a duty on NHS bodies to instruct an IMCA in serious medical treatment decisions when a person who lacks capacity to make a decision has no one who can speak for them. The IMCA is there to support and represent that person and to ensure that decision-making for people who lack capacity is done appropriately and in accordance with the Mental Capacity Act. While they are not there to make a decision for the patient, clinicians have a legal and professional duty to take full account of the information and advice given by the IMCA.

\subsection{Performing endoscopies and completing consent form 4 for patients lacking capacity}

Before making decisions for patients, endoscopists must ensure they are familiar with the law on capacity, as outlined in this document and as relevant to the part of the UK in which they work. Where uncertainty exists, endoscopists and teams caring for patients lacking capacity should seek legal advice.

Decisions for patients who lack capacity are frequently complex. In all circumstances it is essential that the endoscopist satisfies him/herself that the procedure is in the patient's best interests after taking soundings from all relevant individuals and after all necessary adjustments have been made.

In practice many patients will be referred by attending clinicians who know that patient's medical and social circumstances better than the endoscopist. In such a situation, we recommend that there is a multidisciplinary discussion and joint decision between the attending clinician and endoscopist about the best interests of the patient, and the manner in which the decision is made should be recorded in the clinical notes.

For all patients, consent form 4 should be signed by the endoscopist (or nominated deputy), who satisfies him/herself that the procedure is in the patient's best interests. However, when the patient is referred by another clinician, we recommend that, where local policies permit, the attending clinician should sign the consent form 4 before the patient reaches the endoscopy department and the endoscopist should countersign the form. These principles are the same for inpatients and outpatients.

If a patient (either inpatient or outpatient) attends for endoscopy and the endoscopist identifies at this stage that the patient may lack capacity to consent to the procedure, treatment should be delayed until a full assessment has been made by the medical team caring for the patient in conjunction with the relatives and carers, unless it is considered that such a delay would cause additional harm or risk. Further, if it seems possible that capacity may be recovered, the procedure must be delayed until such time as capacity has maximised unless the clinical situation is of such urgency that such delays will be harmful to the patient.

Under these circumstances the endoscopist must make a decision according to the principle of 'best interests' and document the circumstances in the medical case notes.

\subsection{Further details}

For more detail on consent for patients who lack capacity, consult the Reference guide to consent for examination or treatment, available from the NHS response line 08701555455 and at https://www.gov.uk/government/publications/referenceguide-to-consent-for-examination-or-treatment-second-edition.

For further details on LPAs see the Public Guardian website (http://www.publicguardian.gov.uk). More information about LPAs is given in chapter 7 of the Code of Practice (http://www. publicguardian.gov.uk/mca/code-of-practice.htm) and in https:// www.gov.uk/power-of-attorney.

Recommendations 
- We recommend that all endoscopists have sufficient understanding of the law on capacity and in relation to LPA, IMCAs and Advance Decisions to Refuse Treatment, as outlined in this document, to be confident that they can comply with its requirements when assessing capacity and taking consent. Strong recommendation, moderate quality evidence.

- We recommend that where a patient lacks capacity and there is a proxy decision-maker then the decision taken for endoscopy must be taken in the patient's best interests. When assessing a person's best interests the endoscopist must take into consideration the prior wishes of the patient, the views of those caring for the patient or with an interest in his welfare, such as family members. Any intervention must be the least restrictive of the person's future options and freedom. Strong recommendation, moderate quality evidence.

- For patients lacking capacity we suggest that there is a multidisciplinary discussion and joint decision between the attending clinician and endoscopist about the best interests of the patient. The endoscopist should confirm that the procedure is in the best interests of the patient and sign consent form 4. Where local policies permit, both attending team and endoscopist should record their views on the consent form. Weak recommendation, low quality evidence.

\section{WITHDRAWAL OF CONSENT AND REFUSAL OF TREATMENT}

\subsection{When consent is refused}

If an adult with capacity makes a voluntary and appropriately informed decision to refuse treatment, this decision must be respected, except when the treatment relates to a mental disorder, as defined by the Mental Health Act 1983. There may be circumstances where physical treatment is authorised by a court or the Mental Health Act (such as the placement of a feeding tube); it is expected that expert advice will be sought in such exceptional cases.

\subsection{Withdrawal of consent}

A person with capacity is entitled to withdraw consent at any time, including during the performance of an endoscopic procedure. Where a person does object during the procedure the practitioner should, if at all possible, stop the procedure, establish the person's concerns and explain the consequences of not completing it.

At times, appropriate reassurance and further analgesia may enable the practitioner to continue with the person's consent. However, if the patient is in persistent pain, consideration should be given to discontinuing the procedure for reasons of safety, regardless of the patient's consent.

Assessing capacity during a procedure may be difficult. Factors such as prior application of sedation, pain or panic may diminish capacity to consent but the practitioner should try to establish whether at that time the person has capacity to withdraw a previously given consent. In the case of an upper endoscopy, where the patient cannot speak, communication should be established through hand or arm signals. For lower endoscopy, the pros and cons of continuing the procedure can be discussed with the patient.

If the patient appears to have capacity (whether sedated or not) and clearly indicates that he/she wishes the procedure to be discontinued then this must occur immediately unless doing so exposes the patient to significant risk of harm. In difficult or contentious circumstances, it is essential that the endoscopist takes into account the opinion of all of the health professionals present at this time.
If in the endoscopist's opinion capacity to withdraw consent is lacking or uncertain, it may sometimes be justified to continue the procedure in the person's best interests-for example, completing a polypectomy or sphincterotomy that has already begun. If stopping the procedure would put the person at risk of harm, it may be appropriate to continue until that risk no longer applies. However, judgements about capacity during a procedure can be very difficult; under these circumstances the endoscopist should follow the principle that the patient is likely to have capacity and the procedure should be discontinued as soon as it is safe to do so, and the events should be documented in the case notes.

All endoscopy units must have a policy relating to withdrawal of consent. Any circumstances where consent is withdrawn should be noted on the endoscopy report and/or medical case notes.

\subsection{Advance decisions to refuse treatment}

See section 7, 'Patients considered not to have capacity'.

Recommendations:

- We recommend that where a person objects during an endoscopic procedure, the procedure should be stopped, and the person's concerns and capacity to withdraw consent established. It may be possible to restart after a suitable pause and reassurance. Strong recommendation, low quality evidence.

- If the patient appears to have capacity (whether sedated or not) and clearly indicates that he/she wishes the procedure to be discontinued then we recommend that this must occur immediately unless doing so would expose the patient to risk of serious harm. Strong recommendation, low quality evidence.

- We recommend that if, in the endoscopist's opinion, capacity is lacking, it may be justified to continue in the person's best interests. If stopping the procedure would put the person at risk of harm the practitioner may continue until that risk no longer applies. Strong recommendation, moderate quality evidence.

- We recommend that any circumstances in which consent is withdrawn should be noted on the endoscopy report and/or medical case notes. Strong recommendation, low quality evidence.

- We suggest all endoscopy units should have a policy relating to withdrawal of consent. Weak recommendation, low quality evidence.

\section{ADDITIONAL CONSIDERATIONS}

\subsection{Tissue/biopsies}

The Human Tissue Act 2004 (HT Act) covers England, Wales and Northern Ireland with the exception of the provisions relating to the use of DNA, which also apply to Scotland. ${ }^{19}$ The HT Act established the Human Tissue Authority to regulate activities concerning the removal, storage, use and disposal of human tissue. There is separate legislation in Scotland-the Human Tissue (Scotland) Act 2006. Human tissue is referred to in the Act as 'relevant material' and is defined as material that has come from a human body and consists of, or includes, human cells. The Act requires that consent is obtained before a person's organs and tissue can be stored or used for purposes such as research, post mortem examination and transplantation.

Subsequently, nine codes of practice have been published that give practical guidance to professionals carrying out activities which lie within the Human Tissue Authority's remit. Most relevant here is the guidance on code of practice for consent in relation to human tissue. ${ }^{20}$ 
Under the HT Act, consent from the living is needed for storage and use of tissue for:

- obtaining scientific or medical information which may be relevant to any person including a future person

- public display

- research in connection with disorders, or the functioning, of the human body

- transplantation.

Under the HT Act, consent from the living is not needed for storage and use of tissue for:

- education or training relating to human health (including training for research into disorders, or the functioning, of the human body)

- performance assessment

- public health monitoring

- quality assurance.

In practice, for endoscopy this means that consent must be sought for obtaining diagnostic tissue samples and that additional specific consent must also be sought for these samples to be stored and used for future research. Information about obtaining and storing tissue samples should be provided in the standard patient information leaflets. Hospital Trusts should also have their own policies for consent to storing samples for future research.

\subsection{Photography, video and video conferencing}

The DoH guidance (2009) stated that consent should be obtained for any visual or audio recording, including photographs or other visual images. ${ }^{5}$ It also stated that the purpose and possible future use of the recording must be clearly explained to the person before their consent is sought for the recording to be made. However, subsequent guidance from the GMC is provided in the 2011 document "Making and using visual and audio recordings of patients". ${ }^{21}$ In this it is stated that consent to make recordings (video or photographic) of laparoscopic and endoscopic images is implicit in the consent given for the procedure and does not need to be obtained separately.

Furthermore, the GMC states that you may disclose or use any such recordings taken as part of patient care for 'secondary purposes' without seeking consent, provided that before use the recordings are anonymised. This includes purposes such as teaching, training or assessment of healthcare professionals and students, research or other health-related uses which are not designed to benefit the patient directly.

However, when seeking consent for endoscopic investigation or treatment that involves taking such photos or videos, you should, where practicable, explain that such a recording will be made and could be used in anonymised form for secondary purposes, including in the public domain. This information should be included in the patient information leaflet.

Recordings made as part of the patient's care form part of the medical record, and security should be the same as for written material. Thus, patient-identifiable images or data should not be stored on personal mobile devices that may then be removed from the hospital. Most organisations will have a local policy on data capture and retention, which should be adhered to.

Recordings that do not form part of patient care-for example, videos of therapeutic procedures intended solely for presentation at meetings, or video-conferencing (eg, as part of a LEE), require that you follow GMC guidance for making recordings for secondary purposes. Here the GMC states that you must obtain consent before such recordings and that it is good practice that consent is confirmed in writing.

The amount of information you should provide before seeking consent for LEEs or presentations will vary but should include the purpose of the meeting, who will be in the audience, what information will be transmitted, whether it is anonymised or not and should deal with the concerns of the individual patient. Before making the recording, you should explain to patients that they may withhold or withdraw consent during the video conference, and this will not affect the quality of care they receive or their relationship with those providing care.

Further advice in relation to LEEs has been provided by the European Society of Gastrointestinal Endoscopy (ESGE). ${ }^{22}$ For LEEs, patients must be informed in advance of the proposal to include them, and that an additional separate informed consent form must be signed. The ESGE specifically recommends the use of an endoscopist patient advocate for consent. Patients should be informed that there is no additional benefit expected from being treated in a LEE as compared with a routine setting and if they do refuse, their endoscopic procedures must be performed outside the LEE without significant delay. Every attempt should be made for patients to be unidentifiable during the event, but patients should be informed that this may be difficult during procedures by mouth.

Sometimes you may wish to make a recording specifically for education, publication or research purposes during an endoscopic procedure but the patient is temporarily unable to give or withhold consent because, for example, they are sedated. In such cases, you may make such a recording, but you must seek consent as soon as the patient regains capacity. You must not use the recording until you have received consent, and if the patient does not consent, the recording must be immediately destroyed.

Recommendations:

- We recommend that taking photos or videos during normal patient care in endoscopy does not require additional consent, but should be noted in the patient information leaflet. Strong recommendation, moderate quality evidence.

- We recommend that recordings taken at such times may be used for secondary purposes, such as teaching or assessment, without seeking additional consent, so long as the images are anonymised. Strong recommendation, moderate quality evidence.

- We recommend that patient identifiable images or data should not be stored on personal mobile devices. Local employers' policies on data capture and retention must be followed. Strong recommendation, low quality evidence.

- We recommend that video transmission, as in LEEs or for presentation that does not form part of standard patient care, requires additional written consent from the patient. Strong recommendation, moderate quality evidence.

\subsection{Trainees performing endoscopy}

It is essential that trainees are permitted to perform endoscopy under close supervision. Supervising trainees to a level that minimises risk or discomfort to the patient requires an enhanced level of endoscopic skill by the supervisor. Recommendations for training and supervision have been laid out in England by the Joint Advisory Group for endoscopy and Trusts must follow these regulations carefully.

In its guidance, the GMC states that patients must be informed about "the people who will be mainly responsible for and involved in their care, what their roles are, and to what extent students may be involved". 2 Thus, patients attending for endoscopy must be informed ahead of the procedure if there is a possibility that trainees may be present in the endoscopy room, or may be performing the procedure. This information should be included in the information leaflets, and patients should be made aware that they have the right to refuse to allow 
a trainee to perform the procedure, without prejudicing their future access to treatment, but should also be advised that this is an essential part of the training of endocopists (see sections 6.1.4 and 6.2.3).

The consent form should state clearly if a trainee will be performing the procedure and best practice would include the grade and profession of the endoscopist performing the procedure. All endoscopists (including named supervising endoscopist) involved in the procedure must be documented on the report. Responsibility for obtaining consent can be delegated to a trainee under supervision, but the ultimate responsibility to verify the validity of this consent remains with the supervising endoscopist (see section 6.2.1).

\subsection{Nurse-led consent}

Consent can be safely delegated to endoscopy nurses, but must be supported by the individual's Trust and undertaken only after the successful completion of competencies that include direct observational practice evaluation and supporting evidence of learning. ${ }^{23}$ Annual revalidation of knowledge and skills through appraisal, and evaluation of nurse-led consent from patient satisfaction surveys, are essential.

Competencies should include as a minimum a working knowledge and understanding of the following:

- the range of diagnostic and therapeutic procedures and associated risks performed within the endoscopy unit for which they will be obtaining consent;

- the patient information used to support the procedures performed;

- the ethical and legal issues in gaining informed consent;

- national legislation, including the Mental Capacity Act;

- the consent process, including withdrawal of consent.

Recommendations:

- We recommend that consent can be delegated to endoscopy nurses who have successfully completed competency training including direct observational practice evaluation. Strong recommendation, low quality evidence.

- We recommend annual evaluation of patient experience of the consent process and revalidation of knowledge and skills of individuals. Strong recommendation, low quality evidence.

\section{DOCUMENT LIBRARY REQUIRED BY ENDOSCOPY DEPARTMENTS, AUDIT AND RESEARCH REQUIREMENTS}

\subsection{Document library}

This should include:

- information leaflets specific to the unit, for all commonly performed procedures, including a log stating when they were last updated and by whom; each leaflet must be reviewed annually by endoscopy staff;

- information leaflets and consent forms should be available in languages common to the local population and should be reviewed by lay people;

- standardised consent forms for all common procedures;

- Unit and/or Trust policy on consent;

- Unit and/or Trust policy on withdrawal of consent.

\subsection{Mandatory unit audits for consent}

We recommend that the following elements of the consent process are audited:

- Key performance indicators for consent:

- an annual observation audit of a selection of endoscopists;

- consent form signed outside the procedure room;

- outpatients-information (written or verbal) provided before attendance in the endoscopy unit;
- checklist completion;

- quality of consent forms: legibility, grade of endoscopists on form, presence of trainees documented;

- copy of consent form provided to patient;

- inpatients-written information provided and complex procedures discussed with patient before attendance in the endoscopy unit;

- patients who lack capacity-correct completion of form according to local policy.

- Annual patient survey of quality of consent process, including timeliness of provision of written and verbal information.

\subsection{Recommendations for future research}

- When should information best be provided, in what format and by whom to maximise retention and understanding before the procedure?

- How is information of the risk of endoscopy best presented to patients?

- Patient preferences for level of risk provided.

- Evaluation of safer endoscopy checklists.

\section{Author affiliations}

${ }^{1}$ Department of Gastroenterology, Leeds Teaching Hospitals NHS Trust, Leeds, UK ${ }^{2}$ Nurse Consultant, Department of Gastroenterology Wye Valley NHS Trust, UK

${ }^{3}$ Medical Defense Union and Department of Hepatology, Leeds Teaching Hospitals NHS Trust, Leeds, UK

${ }^{4}$ Barrister, London, UK

${ }^{5}$ Crohn's \& Colitis UK Leeds \& District Group, St Albans, UK

${ }^{6}$ Prime Endoscopy, Bristol, UK

${ }^{7}$ St Mark's Hospital, Imperial College London, London, UK

${ }^{8}$ Centre for Paediatric Gastroenterology and International Academy for Paediatric

Endoscopy Training, Sheffield Children's Hospital NHS Foundation Trust, Sheffield, UK

${ }^{9}$ Barrister, Manchester, UK

Contributors The manuscript was drafted by two lead authors (SME and HG). All members of the guideline development group (GDG) reviewed the manuscript and contributed sections relevant to their areas of expertise. All members of the GDG reviewed and voted on all of the recommendations according to the process described in 'Methods'. The manuscript was reviewed by Counsel (KA and KMTN) for accuracy.

Competing interests None declared.

Provenance and peer review Not commissioned; externally peer reviewed.

\section{REFERENCES}

1 Brouwers MC, Kho ME, Browman GP, et al. AGREE Next Steps Consortium. AGREE II: Advancing guideline development, reporting and evaluation in healthcare. CMAJ 2010;182:E839-42.

2 General Medical Council. Consent: patients and doctors making decisions together. 2008.

3 Mental Capacity Act, 2005. http://www.legislation.gov.uk/ukpga/2005/9/contents (accessed Mar 2016).

4 Adults with Incapacity (Scotland) Act, 2000. http://www.legislation.gov.uk/asp/ 2000/4/contents (accessed Mar 2016).

5 Reference guide to consent for examination or treatment (second edition) https:/l www.gov.uk/government/publications/ reference-guide-to-consent-for-examination-or-treatment-second-edition (accessed Mar 2016).

6 Mental Capacity Act Code of Practice, 2007. https://www.gov.uk/government/ publications/mental-capacity-act-code-of-practice (accessed Mar 2016).

7 A Good Practice Guide on Consent for Health Professionals in NHS Scotland, 2006. http://www.sehd.scot.nhs.uk/mels/HDL2006_34.pdf (accessed Mar 2016).

8 Adults with Incapacity (Scotland) Act 2000: Code of Practice (Third Edition): For Practitioners Authorised to Carry Out Medical Treatment or Research Under Part 5 of the Act http://www.gov.scot/Publications/2010/10/20153801/0 (accessed Mar 2016).

9 Department of Health Social Services and Public Safety: Reference Guide to Consent for Examination, Treatment or Care. https://www.dhsspsni.gov.uk/publications/ consent-guides-healthcare-professionals (accessed Mar 2016).

10 Department of Health. Reference Guide to Consent for Examination or Treatment, second edition, 2009.

11 https:/Www.supremecourt.uk/decided-cases/docs/UKSC_2013_0136_Judgment.pdf 
12 Haynes AB; Weiser TG; Berry WR, et al. Safe Surgery Saves Lives Study Group. A surgical safety checklist to reduce morbidity and mortality in a global population. N Engl J Med 2009;360:491-9.

13 Matharoo M, Thomas-Gibson S, Haycock A, et al. Implementation of an endoscopy safety checklist. Frontline Gastroenterol 2014;5:260-5.

14 NHS England. National Safety Standards for Invasive Procedures (NatSSIPs) https:/l www.england.nhs.uk/patientsafety/wp-content/uploads/sites/32/2015/09/ natssips-safety-standards.pdf (accessed Mar 2016).

15 General Medical Council. 0-18 years: Guidance for all Doctors. 2007.

16 Family Reform Act, 1969. http://www.legislation.gov.uk/ukpga/1969/46 (accessed Mar 2016).

17 http://www.legislation.gov.uk/uksi/2006/1832/contents/made (accessed Mar 2016).
18 Department of Health. Confidentiality: NHS Code of Practice. 2003.

19 Human Tissue Act, 2004. http://www.legislation.gov.uk/ukpga/2004/30/contents (accessed Mar 2016).

20 Human Tissue Authority. Code of practice 1. Consent. Version 14. 2014. https:// www.hta.gov.uk/code-practice-1-consent (accessed Mar 2016).

21 General Medical Council. Making and using visual and audio recordings of patients. 2011.

22 Dinis-Ribeiro M, Hassan C, Meining A, et al. Live endoscopy events (LEEs): European Society of Gastroenterology Position Statement-Update 204. Endoscopy 2015;47:1-7.

23 Walozkova J, Avey F, Leahy A. Nurse vs doctor consent within endoscopy: are they equal? Gut 2012;61(Suppl 2):A1-2. 